\title{
The Impact of Neuro-Linguistic Programming on English Language Teaching: Perceptions of NLP-Trained English Teachers
}

\author{
Muhammed Salim Keezhatta ${ }^{1}$ \\ ${ }^{1}$ Department of English, College of Science and Humanities in Al-Kharj, Prince Sattam Bin Abdulaziz University, \\ Alkharj, Saudi Arabia \\ Correspondence: Muhammed Salim Keezhatta, Department of English, College of Science and Humanities in \\ Al-Kharj, Prince Sattam Bin Abdulaziz University, Alkharj (11942), Saudi Arabia. E-mail: \\ m.keezhatta@psau.edu.sa
}

Received: October 20, 2019 Accepted: November 18, 2019 Online Published: November 24, 2019

doi:10.5539/ijel.v9n6p454

URL: https://doi.org/10.5539/ijel.v9n6p454

\begin{abstract}
This study aims at exploring the feasibility of Neuro-Linguistic Programming (NLP) in English Language Teaching (ELT) by analysing the perceptions of NLP-trained English teachers. The study applied a qualitative method based on interviews with 20 NLP-trained English teachers of high schools in India. To acquire an in-depth perspective of the extensive and comprehensive material available, the interview comprised open-ended detailed questions on the innovation, role, different techniques, and benefits and limitations of NLP, while also dwelling upon the different perceptions of NLP-trained language teachers, motivations of the learners towards NLP, and the positive changes brought about by NLP in the education sector. The researcher used a manual thematic analysis method to identify similarities in pattern while performing the analysis. Also, reliable studies from verifiable sources were selected for further analysis. Findings showed that NLP facilitated communication and encouraged learners of English. In addition, the finding strongly suggests NLP as an effective tool for developing teacher-student relationship and for promoting interactive learning environment.
\end{abstract}

Keywords: Neuro-linguistic programming (NLP), English Language Teaching (ELT), NLP techniques, EFL, NLP-trained teachers

\section{Introduction}

\subsection{Research Background}

In English Language Teaching there are various methods and techniques available today. However, new methods are found and experimented to make it more effective. Neuro-linguistic programming (NLP) is an approach for teaching language that helps to attain excellence in learners' performance; but the impact of NLP techniques of in instructors' discourse on learners are petite (Millrood, 2004). NLP allows people to understand at least a small part of the world using all their senses. This view of the world is strained by know-how, perceptions, faith, worth, and sensory systems that are used in many fields such as trade, literacy, training, treatment, and discussion to achieve better results (Bandler \& Grinder, 1976). NLP methods and tools which can be used in the classes for creating an impression on relationships, action, learning and student achievement, and teaching efficiency. The increased access to learning for young people improves their opportunities and achievement. The goal of the teacher in classroom practice is to increase benefits in a cost-effective and productive way to the ever-increasing count of learners (Carey, Churches, Hutchinson, Jones, \& Tosey, 2010). NLP is a subjective experience which will improve our interpersonal communication. NLP can be applied to different kinds of learners (auditory, visual, and kinaesthetic) using pictures, sounds, and emotions. It is a programme which can be adapted to any kind of learners and is a technique which is suitable for English classes. One of the multiple methods is swishing in which we eliminate a harmful stimulus (Moharamkhani et al., 2016).

Some NLP techniques have been included in the advance-teaching programme because they have been recognized as significant for developing the communication skill in teaching, and for improving subject knowledge, both of which are vital to the art of teaching and school leadership (Carey et al., 2010). According to Silva (2017), the mechanism of communication involves four basic elements: our physiology (body), our thoughts (the focus of our attention), our language (words), and our perceptions (beliefs). Both verbal communication and non-verbal communication reflect our feelings and thoughts. We act by following our values and belief systems. Therefore, 
the teacher in the classroom clearly understands students' behaviours and attitudes by following the principles, rules and regulations of conduct that she/he regards as appropriate. The way we communicate decides how we are thought of by our addressees. Emotions are one of the factors which influence the learning process. Learning which is based on fear and tension will bring only stress and panic in students' academic life. Moreover, it negatively affects the assimilation of the materials being taught. It is necessary that teachers gain a capacity to manage the feelings of students, thus making them learn in a delightful, energetic, and calm manner. Another vital element which help students to do their best is to teach them according to their specificities and wants (Silva, 2017).

\subsection{Study Problem}

Students are not exposed to a large variety of vocabulary to understand the text because they are not familiar with words and their meanings. Accordingly, they would face many difficulties with regard to sentence formation and communication. Some students have a problem in learning and putting into use word collocations, idioms, phrasal verbs, and the changes in words with respect to region (Shelby, 2010). The educational sector is becoming more research-driven. The researchers have identified specific psycho-pedagogical problems. In general, we can see that students have an increasing negativity towards the learning environment. As a reaction to this negativity, it is expected from teachers to develop a learning method as simple as possible by securing a productive relationship between the teachers and the learners. NLP has become an unavoidable part of the learning process to attain the needs of the learner (Alroudhan, 2018). Learning the English language is becoming easier and more accessible. However, nowadays there are many issues that could potentially bring negativity to the learning process, thereby rendering it ineffective. The changes that NLP brings in the classroom settings may facilitate effective communication in the process of learning. To overcome the problems resulting from the teaching in this kind of environment, English teachers should encourage and reinforce their students' learning. It can be observed that there is a notable change in high school level when the relationship between English language learning and NLP is studied (Pishghadam, Shayesteh, \& Shapoori, 2011).

\subsection{Study Questions}

This study seeks to answer the following questions.

1) How does NLP influence EFL teaching and learning?

2) What are the NLP-trained language teachers' perceptions about the role played by NLP in English Language Teaching (ELT) classrooms?

\subsection{Objectives}

This study aims at:

1) evaluating the effectiveness of NLP techniques on the motivation level of ELT classroom

2) identifying the perceptions of NLP-trained language teachers about the role of NLP in ELT classroom

3) evaluating the effectiveness of different NLP strategies

4) examining the effect of NLP techniques on the efficacy of ELT

\subsection{Significance of the Study}

NLP being a method of governing the mind on the basis of feelings implies success in the field of language learning (Moharamkhani et al., 2016). NLP has also affected the life of university students. It has significantly influenced families, and students' personal experience and has helped the student in achieving individual fulfilment. Students have used these methods to develop a positive relationship with each other and made sure there was better communication between people. NLP principles have been useful for students in making better decisions and building a calmer environment. The students use NLP to promote communication skills, to hoist the operation of appearance, remembrance, and intellectuality (Salami, 2015).

There is a greater possibility for NLP to be used extensively in the setting of EFL classroom. It has played an essential role in providing classroom instruction to students. NLP is also used to gain excellence in student's performance. Integration of NLP should be done into classroom settings because it offers a new method for discussing innovative ideas and grammatical points, e.g., gestures and reading aloud of opinion, which is written on the board, can be used to express them (Richards \& Rodgers, 2014). This program provides a chance for all learners to attain the possibilities of learning something in the classroom setting, and it is also beneficial in achieving the advancement of English instruction (Ilyas, 2017). It also ensures the learners in the classroom about the condition of learning and exploring by improving their communication skills by ensuring equality among 
students in the process of learning. NLP techniques can be put in practice in daily classroom environment as they play a vital part in improving communication skills and learning, as well as removing the stress in students and helping them achieve success (Alroudhan, 2018).

\subsection{Scope of the Study}

NLP has a significant influence on the students' lives because it is capable of enhancing the calibre of life. Students develop a positive way of thinking and ideas about their lives and are provided with a helping hand in overcoming problems in their lives. Both personal problems and psychological issues were overcome by changing the attitude of students and enhancing their positive behaviour (Turan et al., 2016). NLP has become a very significant tool in students' lives as it facilitates overcoming various difficulties and encouraging personal growth with acquisition of knowledge.

\section{Literature Review}

\subsection{Understanding the Concept of NLP}

The advent of NLP has provided the necessary scope for innovation in all the fields. There is no one definition that appropriately justifies what NLP entails. The proponents of NLP, Grinder and Bandler define (1976) NLP as an explicit model of human experience and communications. Based on linguistic and behavioural patterns as posited by Richard Bandler and John Grinder (1976), NLP endorses the use of mental models that could be used by others in different areas of life such as work, school, health, emotions, and business and interpersonal relationships (Silva, 2017). NLP is a psychological field that deals with the internal subjective world. It is a model which enables an individual to perceive how thoughts are processed and ascertain its impact on the overall behaviour and decision-making. Studies have been conducted to decode the role of NLP in healthcare and how it has profusely caught the interest of doctors, healthcare professionals, and managers (Sturt et al., 2012). According to Grinder and Bandler (1976), it is described as an analysis of subjective experience (Dilts, Grinder, Bandler, \& DeLozier, 1980). The strategies of NLP impel the language learners and teachers alike in order to make the process of teaching-learning more effective and goal-oriented. In addition, it enhances the core competencies of learners (Siddiqui, 2018).

\subsection{NLP Techniques for English Language Teaching Classes}

The use of NLP in the classroom is discernible in India and other countries as well. Classroom activities are now marked by different versions of the current praxis of storytelling, role plays, skits, and simulations and are fervently followed in an ELT classroom (Siddiqui, 2018). An NLP technique that helps create a positive mental image with the systemic aid of 'anchors' or 'triggers' is called anchoring (Helm, 2009). Adopting mirroring as a technique in the classroom is one of the most effective ways to strengthen communication. This technique heavily relies on a person's facial expressions, gestures, postures, and paralanguage that are then used in building a rapport among learners. The utility of these patterns is manifest in the honed and enhanced verbal and non-verbal communication skills (Moore, 2009). In one of the prominent works related to the perceptions of the teachers on NLP in ELT, Targutay (2010) conducted a qualitative study in the background of Turkey and examined the reasons why some NLP techniques and strategies were seen as useful while others were not in teaching a foreign language. The concept of perceptual positioning is another method wherein a situation is examined from the vantage point of a neutral person in a classroom. NLP manufactures a technique to resolve conflicts through neutrality. It could be helpful while teaching English language and guiding the learners to face personal interviews and polishing their negotiation skills (Helm, 2009).

\subsection{Role of NLP in the Classroom}

The significant impact of NLP was realized when the awareness among teachers was raised regarding their power of verbal interaction with the students (Millrood, 2004). NLP helps to channel each student's competency in the right direction as each child interprets the information differently (Silva, 2017). The technique of maintaining flow is an indispensable aspect of NLP that should be implemented in a classroom for successful learning. This flow constitutes activities, challenges, and tasks that would bridge the information gap, thereby injecting a sense of togetherness and belongingness in the students. The flow is sustained in the classroom with the help of jokes, puns, poems, and stories modified to suit the needs of the learners (Stevenson, 2008). In this age, 'chalk and talk teaching method is not enough to teach English effectively' (Susikaran, 2013).

\subsection{Research Gap}

This study primarily focuses on the extensive application of NLP in English teaching and assesses its impact on English language teaching and learning in the high schools of southern India. The researcher tried to analyse the perceptions of NLP-trained English teachers, which was not examined before in Indian context. Although the 
studies and observations by Fritz Perls, Virginia Satir, and Milton Erickson inspired the conception of NLP (Tosey \& Mathison, 2010), more recent interest in NLP has been in the field of education (Moore, 2009). However, these researches have been dedicated to analysing the role of NLP in multiple areas. Research focusing on the effect of NLP in classrooms and analysing the perceptions of NLP-trained English teachers in India is scant. Therefore, this research identifies the gap and contributes to the study in the realm of ELT.

\section{Methodology}

\subsection{Research Approach}

The basic research methodology in the present study is qualitative as it examined the interview transcripts with open-ended questions from 20 NLP certified respondents who were associated with the English teaching sector in the high schools in southern India. To acquire an in-depth perspective of the extensive and comprehensive material available, the interview questions were open-ended and included detailed questions on the innovation, role, different techniques, benefits and limitations of NLP while also dwelling upon the different perceptions of NLP-trained language teachers, motivations of the learners towards NLP, and the positive changes brought about by NLP in the education sector. The researcher observed some classrooms of the teachers to validate their responses to the interview question. Also, reliable studies from verifiable sources were selected for further analysis.

\subsection{Research Design}

As the research needs the investigator to approach NLP-trained teachers from the schools and then formulate a general view, the research design is inductive. Broader generalizations are arrived at as a result of a thorough study of the transcripts available, thereby rendering the design of the research to be inductive. The inductive reasoning follows a particular flow in order to make inferences. The research, thus, follows a bottom-up approach. Since the study followed a qualitative approach, inductive design was best suited to bring out the intricacies of the results obtained.

\subsection{Data Collection}

For the current study, the researcher gathered information through primary data collecting source. Primary data was collected majorly from the interviews with NLP-Trained English Teachers. First-hand interviews with a total number of 20 respondents were conducted to assemble the overarching views vis-a-vis NLP's efficacy in the high school classrooms in India. Post collection, the data were compiled and organized in a suitable manner to prepare them for thematic analysis. Apart from interviews, data were also collected through the observation method wherein the classroom environment and teacher-student dynamics were closely observed. Also, only high schools in the southern part of India were the objects of the research.

\subsection{Sample Size}

The research sample size consisted of 20 NLP-trained English teachers from different high schools in southern India. As NLP is an emerging method, finding experts of NLP-trained English teachers from high schools was an arduous task. So, the number of respondents were limited to 20 . Data were collected through properly structured interviews containing open-ended questions that sought the teachers' responses on the teaching aids they adopted and their efficacy on the students' learning. The sample size included a diverse population. It did not consist of teachers of the same race, caste, creed, gender or background and thus, the data collected was devoid of any kind of social biases. Moreover, the teachers were questioned about their willingness and readiness to adopt new and innovative practices in the classroom and how effective NLP techniques were in determining the success of ELT.

\section{Thematic Data Analysis}

The current study focuses on the extensive application of NLP in English teaching and assesses its impact on the behaviour of students in the high schools of Southern India. Once data are collected, compiled and organized, the study applies a thematic content analysis of the data transcripts that would inadvertently lead to emergence of numerous themes within these data. These data are subsequently highlighted in a distinct manner by bringing to the fore illustrations in correspondence to the themes gleaned from the data transcripts. The analysis was conducted following the steps below:

\subsection{Initial Codes}

In this stage, the data are organized in a significant and orderly way. Coding reduces a large amount of data into small chunks of relevant information. Each segment of data was coded based on their relevance to the study questions (see Table 1). 
Table 1. Initial codes

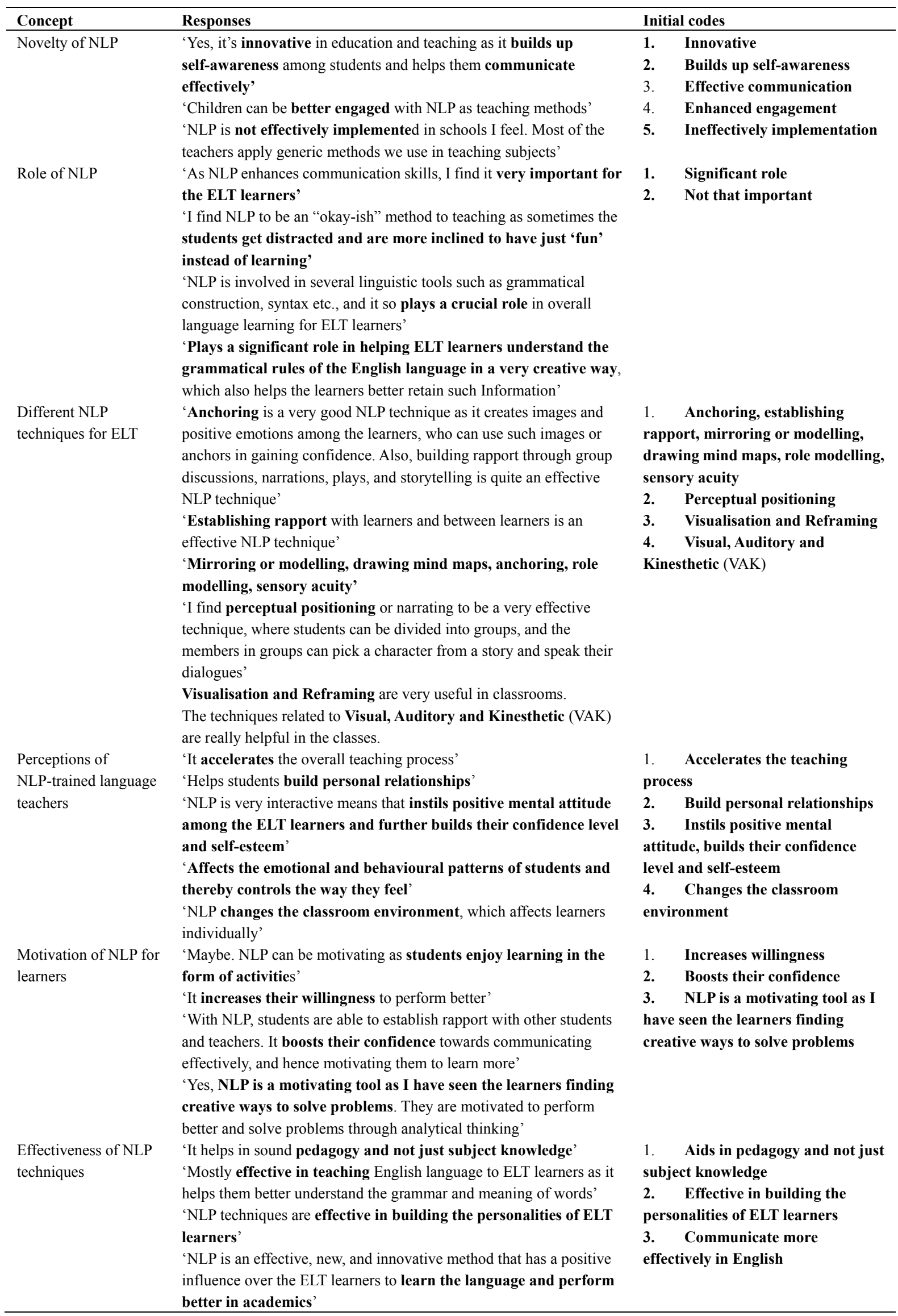


'With rapport building, the ELT learners better understand each other and communicate more effectively in English'

Different effective NLP techniques

Changes by NLP

Benefits of NLP

Criticisms of NLP
'Storytelling, plays, and activities in NLP are effective for the success of ELT learners'

'Games and fun activities such as storytelling increase the communication and persuasive skills of the ELT learners'

'Drawing mind maps and other graphical content'

'Role modelling'

'Anchoring is an NLP technique that is very effective leading to the success of ELT learners as it creates positive images among learners through certain gestures, expressions, and body movements'

'I believe anchoring is a very effective NLP technique but any method used in ELT classrooms must be used regularly to reap maximum benefits'

'The thoughts and action of a learner are changed by NLP techniques'

'NLP does change the learning experience as it provides insights on how body and mind interact'

'Yes, NLP changes the way with which students learn, and it promotes self-motivation to learn as well'

'NLP has a positive impact on one's attitude and emotional

behaviour, that not only helps them improve their communicative skills but also achieve specific goals. It, therefore, has a noticeable change in students' learning experiences'

'NLP creates self-awareness among the students and helps them observe and notice things or actions'

'It brings a slight amount of change as students are more interactive and enjoy learning'

'The most evident benefit is self-motivation through NLP that is applied to both academic and professional life'

'Well in academics, NLP helps students in achieving their goals and makes them more confident towards resolving any problem. In professional life, when considering from a teaching perspective, I think it facilitates the teaching process'

'NLP promotes continuous learning which is crucial for both academic and professional life. In academics, that helps achieve better scores, and in professional, it helps in career progression' 'The use of all senses to understand or process information makes NLP highly beneficial in both academic and professional life' 'People are better able to control their emotions'

'NLP is extremely useful to improve one's communication and behaviour'

'Students can be distracted at times'

'NLP can take a lot of time to organize and implement'

'Sessions can be very time-consuming and children may not always show enthusiasm towards them'

'Difficult to implement NLP methods in ELT classrooms'

'NLP techniques are of no use if they are done once or twice in classrooms. They must be applied regularly, which becomes a challenge when the syllabus to be covered requires more time'

'Not all the teachers are equipped with training on NLP techniques and resources which they can apply in the classrooms'

'Sometimes it might turn difficult to discipline the students when using interactive NLP technique in the ELT classroom'
1. Techniques like storytelling and role modelling

2. Anchoring

1. Yes, it affects the overall learning experiences

2. Promotes self-motivation and self-awareness to learn

3. Positively impacts on one's attitude and emotional behaviour 4. Aids in achieving specific goals

1. Through self-motivation, NLP helps students in achieving their goals and makes them more confident

2. Facilitates the teaching process

3. Promotes continuous learning

4. Career progression

1. Distraction of students

2. Time-consuming

3. Disinterest of children

4. Difficult to implement

\subsection{Searching and Defining Themes}

After the formation of initial codes, the major themes and subthemes of the study were identified by collating the initial codes into potential themes. The codes which were not relevant to the study were removed in this stage. Table 2 corresponds to the major themes identified. 
Table 2. Major themes and subthemes

\begin{tabular}{|c|c|c|}
\hline Sr. No & Themes & Sub-themes \\
\hline \multirow[t]{4}{*}{1} & Novelty and role of NLP & Innovative \\
\hline & & Builds up self-awareness \\
\hline & & Aids communication \\
\hline & & Improves engagement \\
\hline \multirow[t]{6}{*}{2} & Different NLP techniques and their efficacy & Anchoring \\
\hline & & Visualisation \\
\hline & & Reframing \\
\hline & & Visual, Auditory and Kinesthetic \\
\hline & & Storytelling \\
\hline & & Role modelling \\
\hline \multirow[t]{5}{*}{3} & Perceptions of NLP-trained language teachers & Builds personal relationships \\
\hline & & Accelerates the teaching process \\
\hline & & Instils positive mental attitude \\
\hline & & Changes the classroom environment \\
\hline & & Builds their confidence level and self-esteem \\
\hline \multirow[t]{3}{*}{4} & Motivation of NLP for learners & Enjoyment \\
\hline & & Improved performance \\
\hline & & Establishing rapport \\
\hline \multirow[t]{4}{*}{5} & Changes & Thoughts and action \\
\hline & & Learning experience \\
\hline & & Achieving specific goals \\
\hline & & Enhances attitude \\
\hline \multirow[t]{4}{*}{6} & Benefits & Improved teaching process \\
\hline & & Promotes continuous learning \\
\hline & & Enhancing learner's confidence \\
\hline & & Career progression \\
\hline \multirow[t]{4}{*}{7} & Criticism & Distraction of students \\
\hline & & Difficult to implement \\
\hline & & Disinterest of children \\
\hline & & Time-consuming \\
\hline
\end{tabular}

\subsection{Producing the Report-Explanation of Themes}

Having examined the reports on the data collected from the interviews, analysis highlighted seven major themes. These themes can be explained as follows.

\subsubsection{Novelty and Role of NLP}

The respondents of the study were asked whether they think that NLP is an innovation in education and teaching, and if they agree, they should justify their answer. 19 respondents positively replied to the question. For instance, respondent 1 asserted that 'Yes, I believe NLP is an innovative method in the teaching field. It is different than normal or traditional teaching methods as it focuses on forming connections between mind and communication or language used by an individual'. Similarly, respondent 3 said, 'NLP is focused on changing the mental and emotional behaviour of students towards learning. This is definitely an innovative method in education as in general teaching mechanisms, we do not focus on changing the patterns of mental or emotional behaviour'. On the other hand, respondent 9 believed that 'NLP is not effectively implemented in schools I feel. Most of the teachers apply generic methods we use in teaching subjects'. Among all the other respondents, only respondent 9 stated though it is novel, it has not been implemented in most schools. Respondent 11 asserted that "I find NLP to be an "okay-ish" method to teaching as sometimes the students get distracted and are more inclined to have just "fun" instead of learning'.

\subsubsection{Different NLP Technique and Their Efficacy}

When the respondents were asked about the different techniques of NLP and their efficacy, all of them suggested various techniques. Most of them said that anchoring is the best NLP technique. For instance, respondent 10 asserted that 'I believe anchoring is a very good NLP technique as it creates images and positive emotions among the learners, who can use such images or anchors in gaining confidence. Also, building rapport through group discussions, narrations, plays, and storytelling is quite an effective NLP technique that can be used for teaching ELT learners'. Respondent 6 provided a unique reply, stating that "one technique that can be used is drawing mind 
maps. I draw mind maps on board that show the association between new words. This method uses and enhances the visual intelligence of the ELT learners'. Respondent 5 posited, 'role modelling is a very effective NLP technique where the learners learn English and improve by observing and copying others'. Respondents 13,16 \& 17 emphasized the use of visualisation, reframing and VAK factors in ELT classrooms. Teachers using music to create atmosphere and stimulate creativity, or using mime and drama techniques to build confidence and add body language to speech acts are already drawing from the NLP repertoire. These days, however, classroom activities specifically and overtly based on NLP have been developed by ELT practitioners.

\subsubsection{Perceptions of NLP-Trained Language Teachers}

When asked about the perception of NLP-trained language teachers, all of them have positive approach on NLP in ELT. Respondent 1 asserted that 'NLP increases the persuasive and communication skills of the ELT learners. It accelerates the overall teaching process'. Respondent 4 posited that 'NLP in an ELT classroom is very fun as it includes interactive sessions and learning activities. Most techniques involve high communication and that enriches the environment of an NLP classroom'. Similarly, respondent 8 said that 'The students in ELT classrooms are more interactive with each other due to NLP techniques. This helps in building good relations, not only among the students but also teacher-student relationship'. Agreeing with all the respondents, 'NLP in ELT classrooms plays an important role as it helps students in having understanding and following instructions and speak much more fluently'.

\subsubsection{Motivation of Learners for NLP}

Many researches and studies have provided evidence that NLP is a highly effective motivational tool. Respondents for the present study, too, when asked whether they think NLP acts as a motivating tool for learners, 18 respondents agreed to justify it. For example, one of the respondents (1) said that 'NLP is a motivating tool as it instils confidence among the learners with which they can better achieve their goals'. When accounting for the experiences from the respondents, another respondent (11) agreed that, 'In mirroring or monitoring NLP practices, the learners feel motivated to act like their role models and acquire better skills. They are motivated to acquire the skills they admire in others'. Respondent 6 too, agreed, stating that, 'NLP helps achieve goals that the students previously considered impossible. It motivates them to achieve their goals'. Respondent 9 , however, was a bit sceptical and said, 'Maybe. NLP can be motivating as students enjoy learning in the form of activities'. NLP is claimed to help achieve excellence of performance in language teaching and learning, improve classroom communication, optimize learner attitudes and motivation, raise self-esteem, facilitate personal growth in students, and even change their attitude to life. Respondent 12, too, agreed that 'NLP serves as a tool that changes the attitude of students towards a more positive approach in communication. It increases their willingness to perform better'.

\subsubsection{Changes in Learning Experience}

When the respondents were asked if NLP made a noticeable change in students' learning experience, responses of most interviewees were positive. For instance, respondent 10 stated, 'I think NLP does bring some amount of change as the students might better retain visual information that is emphasized upon in NLP techniques'. Similarly, respondent 7 posited, 'Yes, NLP creates self-awareness among the students and helps them observe and notice things or actions carefully'. Respondent 15 said, 'The learning experiences of the students are enhanced with NLP techniques due to higher and better communication among the students'.

\subsubsection{Benefits of NLP}

NLP researchers have studied the most influential orators throughout history. When asked whether the same benefits of NLP were observed in students, 18 of them gave an optimistic reply. For instance, respondent 5 said, 'People are better able to control their emotions and that I consider to be quite a benefit'. 'Well in academics, NLP helps students achieve their goals and make them more confident towards resolving any problem. In professional life, when considering from a teaching perspective, I think it facilitates the teaching process'. Respondent 1 said, 'The most evident benefit is self-motivation through NLP that is applied to both academic and professional life'.

\subsubsection{Criticisms of NLP}

Determining the effectiveness of NLP is challenging for several reasons. NLP has not been subject to the same standard of scientific rigour as more established therapies, such as cognitive behavioural therapy. When the respondents were asked about the adverse or deficient aspects of NLP, diverse responses were received. For example, respondent $1 \& 16$ said, 'I have not really found any difficulties with NLP', whereas respondent 2 stated, 'Sometimes it might turn difficult to discipline the students when using interactive NLP technique in the ELT classroom'. Respondent 3 talked about its importance in just the language subject claiming, 'NLP is best used for 
language teaching, and less applied to other subject areas'. Untrained teachers could not benefit from NLP, as according to respondent 4, 'Not all the teachers are equipped with training on NLP techniques and resources with which they can apply it in the classrooms'. Respondent $6 \& 20$ did not find any such critical issues with NLP.

\section{Discussion and Conclusion}

Discussion of each theme unswervingly led to the various aspects of the study question 1 and 2 . The first theme focused on the novelty and role of NLP in ELT context. It focuses on making a connection between mind and communication or language used by the individuals. As a result, NLP is concerned with changing the mental and emotional behaviour of students towards learning. On comparing this data with existing literature, it was found that the use of NLP has been endorsed by different models in diverse areas such as school education, health care, workplace well-being, emotional development, and business and interpersonal relationships (Silva, 2017; Sturt et al., 2012).

The second theme examined different NLP techniques and their efficacy. It was found that NLP helped teachers to create an atmosphere that stimulates creativity, using mime and drama techniques to build student's confidence. To compare the data with the existing literature review, the study found that NLP is implemented in classrooms in India and other countries where teachers adopt different versions of current practices of storytelling, role-playing, and skits (Siddiqui, 2018). NLP technique also helps to create a positive mental image, and it is considered as one of the most effective tools to strengthen communication (Moore, 2009).

The third theme, which is exclusively related to the study question 2 , investigated the perception of NLP-trained language teachers. It was found that teachers use NLP learning techniques in interactive learning sessions and activities. Most of the techniques involve a high level of communication and create good relations not only among students but also between teachers and students. NLP also helps to channelize the competency of each student in the right direction as each child interprets information differently (Silva, 2017). The study also examined the motivation of learners towards NLP. Several studies have provided evidence that NLP is a highly motivational tool which builds confidence among learners so that they could better achieve their goals. NLP also helps to achieve excellence of performance in language teaching and learning by improving classroom communication, optimizing learner attitudes and motivation, raising self-esteem, and facilitating students' personal growth. Hence, it can be said that NLP was effective when teachers are aware of their power of verbal interaction with students (Pishghadam et al., 2011). Finally, the study also examined the challenges and benefits of NLP and found that NLP makes noticeable changes in students' learning experience so that they will be able to notice, think, and act carefully. NLP also helps students to achieve their goals and makes them more confident towards resolving any problem (Susikaran, 2013).

The relationship between teachers and students plays an important role in the learning outcomes for students, but they also face problems in learning and remembering a number of words. Students are not exposed to a large vocabulary to understand the text because they are not familiar with words and syntax. As a result, it was found that some students have a problem in learning and using fixed words, idioms, and verbs (Shelby, 2010). In this respect, NLP plays an important role in the learning process to meet the needs of the learner (Alroudhan, 2018). As discussed in the literature review section, learning English has become easier nowadays, although several issues could potentially affect the learning process adversely. However, NLP brings positive changes in the classroom and facilitates effective communication in the process of learning. Teachers need to focus on creating such an environment to encourage the learners of English (Pishghadam et al., 2011). The findings of the study also revealed some similarities with a previous study carried out at Bilkent University located in Ankara, Turkey. It stated that NLP was not a set of small-scale teaching techniques, but a broad system of communication that draws on a number of disciplines (Targutay, 2010). NLP principle has been useful for the students with regard to the improvement of their decision-making skills by enabling a calm environment. Hence, it can be said that students can use NLP to develop their communication skills with confidence and mindfulness (Salami, 2015). To sum up, the finding of the study showed that NLP facilitated English communication and encouraged learners of English and strongly suggests NLP as an effective tool for developing teacher-student relationship and for promoting interactive learning environment.

\subsection{Limitations of the Study}

The major limitation of this study was finding experts of NLP-trained English teachers from high schools. Also, the researcher could take the participants from the four southern part of India such as Kerala, Tamilnadu, Karnataka and Andrapradesh. Therefore, further researches should be conducted to generalise the topic in a way that is more meaningful. 


\subsection{Recommendations}

This study offers two major recommendations for teachers. First, teachers are recommended to adopt NLP with the same rigour as more established therapies such as cognitive behavioural therapy to ensure better educational and personal outcomes for students. Second, teachers are recommended to improve the learning experience of students by monitoring the flow of constructive activities, challenges, and tasks that would bridge the information gap and inject a sense of achievement.

\subsection{Future Scope}

NLP can have a significant influence on students' lives because it would enhance their perceptions of themselves and their general outlook about life. Students have developed positive thinking habits and gained confidence in overcoming the problems they face. Change in students' attitude has reduced psychological issues and enhanced their positive behaviour (Turan et al., 2016). NLP has become a very significant tool in student's lives as it has helped them significantly to acquire knowledge and attain personal growth.

\section{References}

Alroudhan, H. E. (2018). The Effect of Neuro-linguistic Programming Coaching on Learning English. International Journal of Applied Linguistics and English Literature, 7(4), 184-190. https://doi.org/10.7575/aiac.ijalel.v.7n.4p.184

Carey, J., Churches, R., Hutchinson, G., Jones, J., \& Tosey, P. (2010). Neuro-linguistic programming and learning: Teacher case studies on the impact of NLP in education. CfBT Education Retrieved from https://www.educationdevelopmenttrust.com/EducationDevelopmentTrust/files/0e/0e67af03-a8ae-40dd-910 5-aa615db2512c.pdf

De Lano, L., Riley, L., \& Crookes, G. (1994). The meaning of innovation for ESL teachers. System, 22(4), 487496. https://doi.org/10.1016/0346-251X(94)90005-1

Dilts, R., Grinder, J., Bandler, R., \& DeLozier, J. (1980). Neuro-linguistic programming (Volume 1: The study of the structure of subjective experience). Meta Publications.

Douglas, D. (2000). Assessing language for specific purposes. Language Testing, 18(2), 133-147. Retrieved from https://pdfs.semanticscholar.org/5fb9/9dbb701fe0e2dae893ababf9b772a07dec79.pdf

Edge, J. (1993). Essentials of English language teaching. New York: Pearson Education, Longman. Retrieved from https://www.scribd.com/doc/69964645/Essentials-of-English-Language-Teaching

Grinder, J., \& Bandler, R. (1976). The structure of magic. Palo Alto (Calif.): Science and Behavior Books.

Helm, D. J. (2009). Improving English instruction through neuro-linguistic programming. Education, 130(1), 110114. Gale Academic OneFile, Accessed 2 Nov. 2019. Retrieved from https://go.galegroup.com/ps/anonymous?id=GALE\%7CA207643767\&sid=googleScholar\&v=2.1\&it=r\&lin kaccess $=$ abs \&issn $=00131172 \& \mathrm{p}=\mathrm{AONE} \& \mathrm{sw}=\mathrm{w}$

Ilyas, M. (2017). Finding relationships between acquisition of basic skills and neuro-linguistic programming techniques. Journal of Literature, Languages and Linguistics, 34. Retrieved from https://repository.psau.edu.sa/jspui/retrieve/2dfd5253-56c3-48a4-99c6-fc608d18b4a8/2016-17_06_NLP_JL LL.pdf

Ketabi, S., \& Kavoshian, S. (2017). Innovative technology in English language teaching: The Utility of mobile social network sites to improve teacher education. Teaching English Language, 11, 39-67.

Millrood, R. (2004). The role of NLP in teachers' classroom discourse. ELT Journal, 58(1), 28-37. https://doi.org/10.1093/elt/58.1.28

Moharamkhani, A., Karimi, L., \& Ahmadi, S. (2016). The impact of neuro linguistic programming (NLP) on EFL learners' vocabulary achievement. IOSR Journal of Humanities and Social Science (IOSR-JHSS), 21(11). Retrieved from https://pdfs.semanticscholar.org/49e9/502b4b86c75273102c2d88b212f9a35d42b4.pdf

Moore, C. (2009). NLP in education. Unpublished M. Sc. thesis, Nui Maynooth University, Ireland.

Pishghadam, R., Shayesteh, S., \& Shapoori, M. (2011). Validation of an NLP scale and its relationship with teacher success in high schools. Journal of Language Teaching and Research, 2(4). https://doi.org/10.4304/jltr.2.4.909-917

Pishghadam, R., \& Shayesteh, S. (2014). Neuro-linguistic programming (NLP) for language teachers: revalidation of an NLP scale. Theory and Practice in Language Studies, 4(10). 
https://doi.org/10.4304/tpls.4.10.2096-2104

Richards, J. C., \& Rodgers, T. S. (2014). Approaches and methods in language teaching. Cambridge University Press. Retrieved from https://epdf.pub/queue/approaches-and-methods-in-language-teaching.html

Salami, S. (2015). Implementing neuro-linguistic programming (NLP) in changing students' behavior: Research done at Islamic University in Ache. Jurnal Ilmiah Peuradeun, 3(2), 235-256. Retrieved from https://journal.scadindependent.org/index.php/jipeuradeun/article/view/65

Shelby, M. (2010). Difficulties in vocabulary learning. Retrieved from http://www.english-forstudents.com/Difficulties-in-Vocabulary-Learning.html

Siddiqui, Z. (2018). English language teaching through NLP: techniques and methods. Research Journal of English Language and Literature, 6(2). Retrieved from http://www.rjelal.com/6.2.18/181-184\%20ZEBA\%20SIDDIQUI.pdf

Silva, D. (2017). Contributions of neurolinguistic programming in school education. EC Neurology, 1, 10-13. Retrieved from https://www.ecronicon.com/ecne/si/ECNE-01-SI-04.pdf

Stevenson, M. (2008). Intro to neuro-linguistic programming.

Sturt, J., Ali, S., Robertson, W., Metcalfe, D., Grove, A., Bourne, C., \& Bridle, C. (2012). Neurolinguistic programming: A systematic review of the effects on health outcomes. British Journal of General Practice, 62(604), e757-e764. https://doi.org/10.3399/bjgp12X658287

Susikaran, R. S. A. (2013). The Use of Multimedia in English Language Teaching. Journal of Technology for ELT, 3(2). Retrieved November 1, 2014, from https://sites.google.com/site/journaloftechnologyforelt/system/app/pages/search?scope=search-site\&q=theu seofmultimediainenglishlanguageteaching

Targutay, M. (2010). The role of neuro-linguistic programming in English language teaching: NLP-trained language teaching practitioners' perceptions about NLP strategies and techniques used in classes. Doctoral dissertation, Bilkent $\quad$ University. $125 . \quad$ Retrieved from http://repository.bilkent.edu.tr/bitstream/handle/11693/15421/0006160.pdf?sequence=1

Tosey, P., \& Mathison, J. (2010). Neurolinguistic programming as an innovation in education and teaching. Innovations in Education and Teaching International, 47(3), 317-326. https://doi.org/10.1080/14703297.2010.498183

Turan, H., Kodaz, K., \& Turan, G. (2016). The effect of NLP education on the teaching profession in Turkey. Department of Human Resource Management, Bursa. https://doi.org/10.31901/24566322.2016/15.1-2.13

Wilkins, D. A. (1972). Linguistics in language teaching. Cambridge, MA: MIT Press. Retrieved from https://shunmarif.firebaseapp.com/bs090/linguistics-in-language-teaching-by-david-arthur-wilkins-0846205 068.pdf

\section{Appendix A}

Q.1 Do you think Neuro - linguistic programming (NLP) is an innovation in education and teaching? If yes, kindly justify it.

Q.2 What is the role of NLP for English as a Foreign Language (EFL) learners?

Q.3 What are the different NLP techniques which may lead to the success of EFL learners?

Q.4 What are the perceptions of NLP-trained language teachers about the role of NLP in ELT classroom?

Q.5 Do you think NLP acts as a motivating tool for learners? Kindly justify your answer.

Q.6 What in your opinion is the overall effectiveness of NLP techniques on ELT learners? 
Q.7 How are different NLP techniques effective for the success of ELT learners? Kindly provide the effectiveness technique-wise.

Q.8 Do you think NLP can make a noticeable change in students' learning experience?

Q.9 What are the benefits that NLP can bring to academic and professional lives?

Q.10 What are the caveats of NLP?

\section{Copyrights}

Copyright for this article is retained by the author, with first publication rights granted to the journal.

This is an open-access article distributed under the terms and conditions of the Creative Commons Attribution license (http://creativecommons.org/licenses/by/4.0/). 